\title{
HDAC inhibitors induce epithelial-mesenchymal transition in colon carcinoma cells
}

\author{
MEIYING JI $^{1 *}$, EUN JEOUNG LEE ${ }^{1 *}$, KI BAE KIM ${ }^{1}$, YANGMI KIM ${ }^{2}$, \\ ROHYUN SUNG ${ }^{3}$, SANG-JEON LEE ${ }^{4}$, DON SOO KIM ${ }^{5}$ and SEON MEE PARK ${ }^{1}$ \\ Departments of ${ }^{1}$ Internal Medicine, ${ }^{2}$ Physiology, ${ }^{3}$ Pathology, ${ }^{4}$ General Surgery and ${ }^{5}$ Orthopedic Surgery, \\ Chungbuk National University College of Medicine, Cheongju 361-711, Republic of Korea
}

Received November 25, 2014; Accepted February 26, 2015

DOI: $10.3892 /$ or.2015.3879

\begin{abstract}
The effects of histone deacetylase (HDAC) inhibitors on epithelial-mesenchymal transition (EMT) differ in various types of cancers. We investigated the EMT phenotype in four colon cancer cell lines when challenged with HDAC inhibitors trichostatin A (TSA) and valproic acid (VPA) with or without transforming growth factor- $\beta 1$ (TGF- $\beta 1$ ) treatment. Four colon cancer cell lines with different phenotypes in regards to tumorigenicity, microsatellite stability and DNA mutation were used. EMT phenotypes were assessed by the expression of E-cadherin and vimentin using western blot analysis, immunofluorescence, quantitative real-time RT-PCR following treatment with TSA (100 or $200 \mathrm{nM})$ or VPA $(0.5 \mathrm{mM})$ with or without TGF- $\beta 1(5 \mathrm{ng} / \mathrm{ml})$ for $24 \mathrm{~h}$. Biological EMT phenotypes were also evaluated by cell morphology, migration and invasion assays. TSA or VPA induced mesenchymal features in the colon carcinoma cells by a decrease in E-cadherin and an increase in vimentin expression at the mRNA and protein levels. Confocal microscopy revealed membranous attenuation or nuclear translocation of E-cadherin and enhanced expression of vimentin. These responses occurred after $6 \mathrm{~h}$ and increased until $24 \mathrm{~h}$. Colon cancer cells changed from a round or rectangular shape to a spindle shape with increased migration and invasion ability following TSA or VPA treatment. The susceptibility to EMT changes induced by TSA or VPA was comparable in microsatellite stable (SW480 and HT29) and microsatellite unstable cells (DLD1 and HCT116). TSA or VPA induced a mesenchymal phenotype in the colon carcinoma cells and these effects were augmented in the presence of TGF- $\beta 1$. HDAC
\end{abstract}

Correspondence to: Professor Seon Mee Park, Department of Internal Medicine, Chungbuk National University College of Medicine, 410 Seongbong-ro, Heungdeok-gu, Cheongju 361-711, Republic of Korea E-mail: smpark@chungbuk.ac.kr

${ }^{*}$ Contributed equally

Key words: colon cancer, epithelial-mesenchymal transition, transforming growth factor- $\beta 1$, trichostatin $A$, valproic acid inhibitors require careful caution before their application as new anticancer drugs for colon cancers.

\section{Introduction}

Colorectal cancer (CRC) is the fourth most fatal cancer in Korea (1). Although the 5-year survival rate of CRC overall has been reported to be as high as $71.3 \%$ (1), the rate for patients with recurrence is $<40 \%$ (2). Epithelial-mesenchymal transition (EMT) is critical for carcinogenesis, tumor invasion, metastasis, chemo-resistance and acquisition of stem cell properties. The EMT phenotype is indicative of a poor prognosis in CRC $(3,4)$. Combined treatment to attenuate or reverse EMT enhances the sensitivity to conventional anti-neoplastic agents and improves oncologic outcomes (5).

Both genetic and epigenetic changes are required for the transformation, promotion and progression of CRC (6). Downregulation of tumor-suppressor genes due to unbalanced histone deacetylase (HDAC) hyperactivity has been reported in CRC. The histone acetylation status may play a role in colon tumorigenesis and re-expression of these genes can be induced by treatment with an HDAC inhibitor in CRC. HDAC inhibitors have been reported to be effective as anticancer agents and, in combination with conventional chemotherapeutics, have been reported to synergistically enhance growth arrest, apoptosis and differentiation in cancer cells (6). These effects in colon cancer cells have currently been demonstrated for many HDAC inhibitors including valproic acid (VPA) (7) and trichostatin A (TSA) (8-11). TSA, a hydroxamate, may have the highest potency against HDAC1, 3 and 8 . VPA, a short chain fatty acid, appears to have the highest activity against HDAC1 and 2, but appears also to affect HDAC3, 4, 5 and 7 at higher doses, showing non-specific sensitivity to HDACs (12). TSA and VPA reduce the growth and survival, induce differentiation, enhance radiosensitivity and reduce chemoresistance (13).

Histone modification has been shown to play a key role in controlling EMT. Many studies have reported that various HDAC inhibitors reverse or attenuate EMT through the upregulation of E-cadherin in different solid tumors such as HCC (14), breast $(15,16)$, esophageal cancer (17) and ovarian tumors (18). In addition, they attenuate TGF- $\beta 1$-induced EMT in different cells: hepatocytes (19), retinal pigment epithelial cells (20), lens epithelial cells (21) and renal epithelial 
cells (22). These results suggest that HDAC inhibitors may have therapeutic roles to reduce EMT. However, recent studies have also reported that HDAC inhibitors induce EMT, reverse stem cell properties and enhance metastasis and invasion in prostate cancer (23), head and neck squamous cell carcinoma (24) and nasopharyngeal carcinoma (25). Whether HDAC inhibitors inhibit or induce EMT in CRC has not yet been reported, and needs to be clarified.

We investigated the effect on the EMT of colon cancer cells induced by the HDAC inhibitors TSA or VPA, alone, and in combination with TGF- $\beta 1$. TGF- $\beta 1$ induced the EMT of colon cancer cells in DNA microsatellite stable (MSS) cells, whereas cells with DNA microsatellite instability (MSI) showed variable responses to TGF- $\beta 1$ (26). Tumor cells with MSI having mutant TGF- $\beta$ receptor type II (TGFBR2) exhibited less EMT and a more favorable prognosis compared to cells with MSS. We selected four CRC cell lines including MSI cells (DLD1 and HCT116) and MSS cells (HT29 and SW480). We evaluated the expression of E-cadherin as an epithelial marker, and vimentin as a mesenchymal marker. The EMT phenotype was also evaluated by cell morphology, migration and invasion assays.

\section{Materials and methods}

Cell lines and culture conditions. We used four colon carcinoma cell lines. DLD1, HT29, HCT116 and SW480 were purchased from the Korean Cell Line Bank (KCLB, Seoul, Korea). These cells were maintained in Dulbecco's modified Eagle's medium (DMEM), containing 10\% heat inactivated fetal bovine serum (FBS), potassium penicillin $100 \mathrm{U} / \mathrm{ml}$, streptomycin $100 \mathrm{~g} / \mathrm{ml}$, $2 \mathrm{mM}$ glutamine and $20 \mathrm{mM}$ sodium bicarbonate. The cells were incubated in $5 \% \mathrm{CO}_{2}$ and $95 \%$ humidity in a $37^{\circ} \mathrm{C}$ chamber. The growth medium was changed every 3 days.

Western blot analysis. Total protein was extracted, and the protein concentration was measured by the Bradford DC protein assay (Bio-Rad Laboratories, Hercules, CA, USA). Then, 20-40 $\mu \mathrm{g}$ protein from each sample was separated on $12 \%$ Bis-Tris polyacrylamide gel through electrophoresis and blotted on immobilon transfer membranes (Millipore, Temecula, CA, USA). Blots were immunostained with vimentin (1:1,000; Sigma-Aldrich, St. Louis, MO, USA) and E-cadherin (1:1,000; Invitrogen, Eugene, OR, USA). The primary antibody was added at $4^{\circ} \mathrm{C}$ overnight, and then the secondary antibody at room temperature for $1 \mathrm{~h}$. Proteins were visualized by using ECL Plus Western Blotting detection reagents (Intron Biotechnology, Seoul, Korea) and measured by image analysis of the Fuji Image Quant software (FujiFilm Las-3000 mini, Tokyo, Japan), according to the manufacturer's instructions.

Quantitative real-time RT-PCR. The total RNA was isolated using the RNase Mini kit (Qiagen, Valencia, CA, USA). The residual DNA was removed using an RNase Free NDase kit (Qiagen). High capacity RNA-to-cDNA kit (Applied Biosystems, Foster City, CA, USA) was used to reverse transcribe $1 \mu \mathrm{g}$ of RNA into cDNA according to the manufacturer's instructions. Real-time PCR was performed using specific primers to quantify gene expression using SYBR-Green RT PCR reagents (Applied Biosystems). The relative amount of
mRNA was normalized to the expression of GAPDH. The primer sequences used in the present study were as follows; GAPDH primer sequences: forward, 5'-CATCAATGGAAA TCCCATCA-3' and reverse, 5'-TTCTCCATGGTGGTGAA GAC-3'; E-cadherin primer pair: forward, 5'-TTCTGCTGC TCTTGCTGTTT-3' and reverse, 5'-TGGCTCAAGTCAAA GTCCTG-3; Vimentin primer pair: forward, 5'-GCCCTTA AAGGAACCAATGA-3' and reverse, 5'-AGCTTCAACGG CAAAGTTCT-3'. The PCR reactions were repeated three times in three independent experiments.

Immunofluorescence microscopy. Individual sterile coverslips were placed in the wells of a 4-well plate and colon carcinoma cells were added and incubated for $24 \mathrm{~h}$. Subsequently, the cells were treated with $10 \mathrm{ng} / \mathrm{ml}$ TGF- $\beta 1,100$ or $400 \mathrm{nM}$ TSA, $0.5 \mathrm{mM}$ VPA diluted in DMEM media with $1 \%$ FBS for $48 \mathrm{~h}$. After washing with PBS, the cells were fixed in $3.7 \%$ paraformaldehyde for $20 \mathrm{~min}$ at room temperature. The paraformaldehyde was removed and cells were washed with PBS. Blocking solution was then added for 30 min to prevent nonspecific binding, and then incubation was carried out using anti-E-cadherin (1:100; Cell Signaling Technology, Danvers, MA, USA) and anti-vimentin (1:100; Leica Microsystems, Wetzlar, Germany) as the primary antibodies, overnight, at $4^{\circ} \mathrm{C}$, on a rocking platform. The washed slides were incubated for $1 \mathrm{~h}$ at room temperature with 1:100 dilutions of Alexa-488 anti-rabbit IgG (H+L) (Molecular Probes Inc., Eugene, OR) secondary antibody, and Alexa-568 goat anti-mouse $\operatorname{IgG}(\mathrm{H}+\mathrm{L})$ (Molecular Probes) secondary antibody. They were washed again, mounted with Vectashield mounting medium (Dako, Carpinteria, CA, USA), and examined using Leica Zeiss optics in the Core Facility of Chungbuk National University. We also captured immunofluorescence images at time-points of 6, 12, 24 and $48 \mathrm{~h}$ to evaluate the protein translocalization.

Cell invasion and migration assays. We evaluated cell invasion and migration ability in the MSI or MSS cell lines. DLD1 and SW480 were selected. DLD1 and SW480 cells were seeded in 96-well plates over a homogeneous thin layer of fibronectin (BD Biosciences, Bedford, MA, USA) in a Millicell cell culture insert (Millipore) that contained polycarbonate filter membranes with 8-mm diameter pores. Tumor cells from the control group were maintained in DMEM supplemented with $1 \%$ FBS and $1 \%$ antibiotics, and the HDAC inhibitor group received $100 \mathrm{nM}$ of TSA or $0.5 \mathrm{mM}$ VPA diluted in media. The lower chamber contained DMEM supplemented with $10 \%$ FBS and $1 \%$ antibiotics. After plating, the cells were incubated for $24 \mathrm{~h}$ at $37^{\circ} \mathrm{C}$ in a $5 \% \mathrm{CO}_{2}$-humidified incubator. Invasive cells in the lower chamber were stained with hematoxylin and eosin (H\&E). Images were captured using a QImaging Exi Aqua monochrome digital camera attached to a Nikon Eclipse $80 \mathrm{i}$ microscope (Nikon Inc., Melville, NY, USA) and visualized using QCapture Pro software.

The cells were allowed to grow in $10 \%$ FBS containing DMEM to confluency in a 6-well plate. A central linear wound was made with a 200-ml sterile pipette tip and then the cells were washed with PBS twice. Afterwards, the HDAC inhibitor group received $100 \mathrm{nM}$ of TSA or $0.5 \mathrm{mM} \mathrm{VPA}$ and $10 \mathrm{ng} /$ $\mathrm{ml}$ TGF- $\beta 1$ diluted in media with $1 \%$ FBS. Plates were photographed after 0,24 and $48 \mathrm{~h}$. 


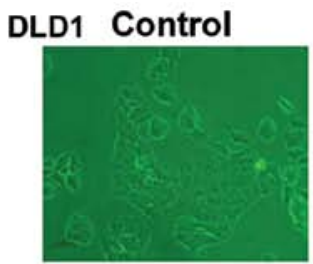

HCT116

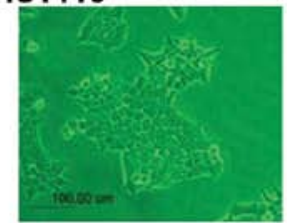

SW480

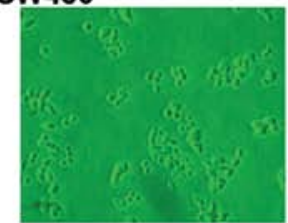

HT29

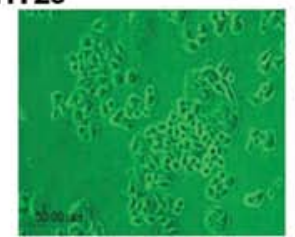

TSA $200 \mathrm{nM}$

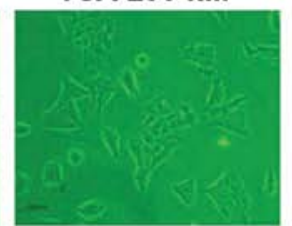

TSA $100 \mathrm{nM}$

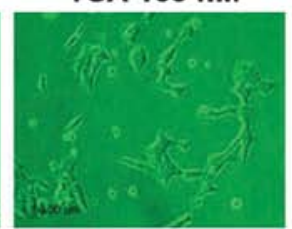

TSA $100 \mathrm{nM}$

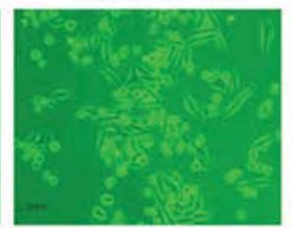

TSA $100 \mathrm{nM}$

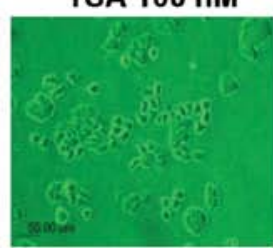

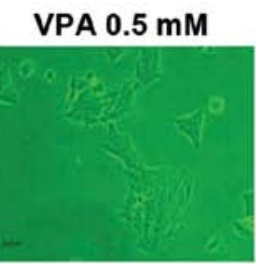
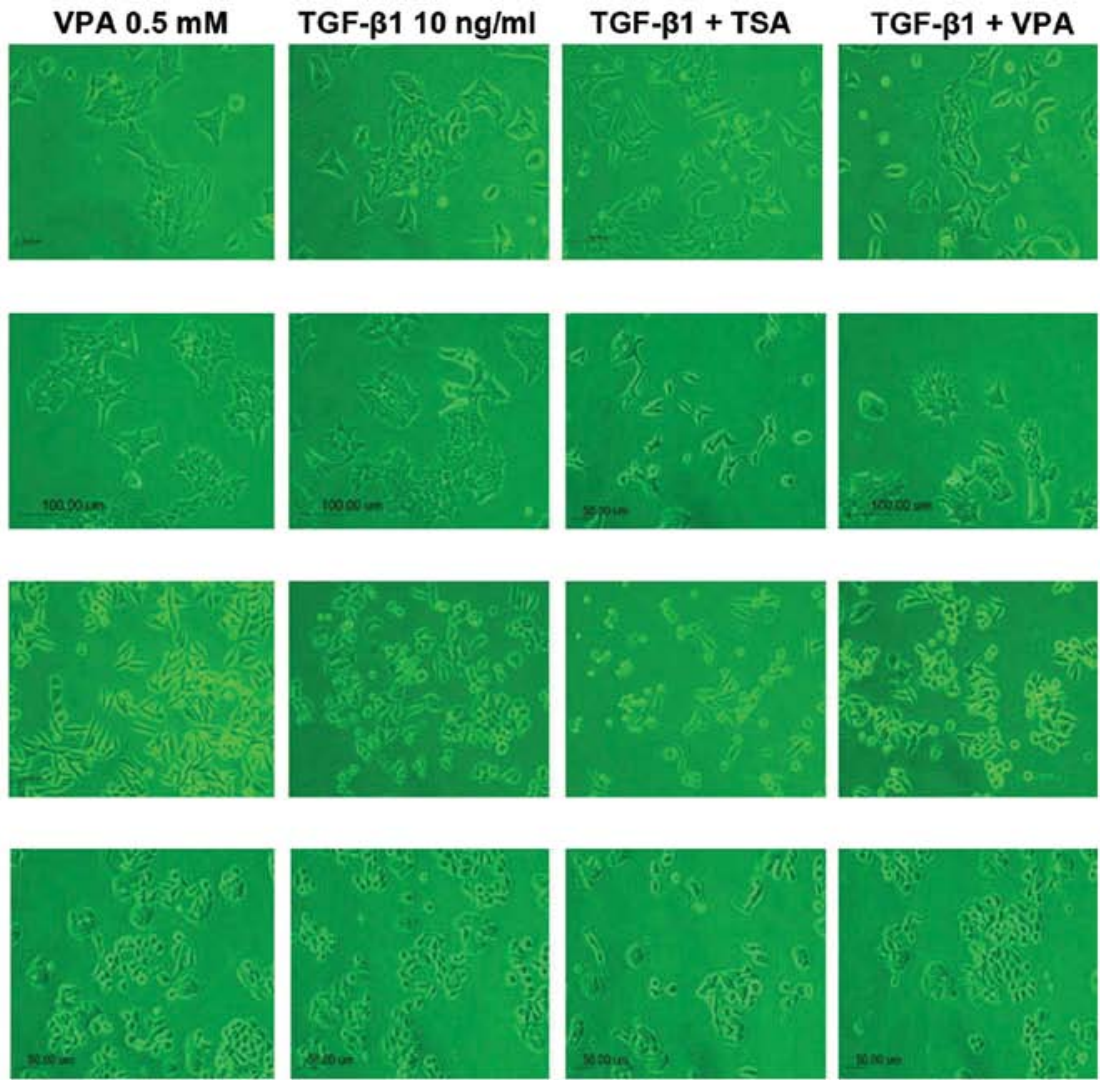

Figure 1. TSA and VPA induce a mesenchymal phenotype. Colon cancer cells treated with TSA or VPA alone or combined with TGF- $\beta 1$ for $24 \mathrm{~h}$ at the indicated doses exhibited a fibroblastic-type phenotype, while cells with no treatment displayed rounded epithelial cell morphology (original magnification, x100).

Cytotoxicity assay. Cell viability was assessed using Promega cell proliferation MTS assay (Promega, Madison, WI, USA). Briefly, CRC cells were seeded in 96-well plates at a density of $1 \times 10^{3} /$ well and incubated with increasing concentrations of TSA, VPA and TGF- $\beta 1$ for $48 \mathrm{~h}$ to determine a dose-response curve. Subsequently, dead cells were washed away, the attached cells were incubated with MTS, and cell viability was detected using microplate reader Model-680 (Bio-Rad Laboratories). All the experiments were conducted in triplicate.

Statistical analysis. The SPSS 16.0 software (IMB, Armonk, NY, USA) was used to analyze the data. The differences between groups were evaluated using the Mann-Whitney $\mathrm{U}$ test and Wilcoxon signed-rank test, with $\mathrm{P}<0.05$ being considered to indicate a statistically significant result.

\section{Results}

Cell morphology. The four CRC cell lines were altered from round or rectangular-shaped cells to spindle-shaped cells with loose cell-cell contact following TSA or VPA treatment or TGF- $\beta 1$ treatment. The response to TGF- $\beta 1$ treatment in the DLD1 and HCT116 cells was not prominent compared to the SW480 and HT29 cells. However, the morphological changes induced by TSA and VPA treatment were similar in both the MSS and MSI cell lines. Morphological changes were most prominent in the SW480 cells, which were distributed as single round cells. However, the HT29 cells showed minor changes compared to the SW480 cells. DLD1 and HCT116 cells showed a wider gap between cells and were spindleshaped. The morphological changes were similar following TSA or VPA single treatment or in combination with TGF- $\beta 1$ treatment (Fig. 1).

Nuclear localization of E-cadherin and increased expression of vimentin in the colon cancer cells. The four CRC cell lines showed attenuation of membrane expression and nuclear translocation of E-cadherin and/or increased vimentin expression following TSA and VPA treatment in both the MSI and MSS cell lines (Fig. 2A-D). The effects of TSA and VPA treatment on the DLD1 cells differed; TSA induced changes in E-cadherin expression, whereas VPA had effects on vimentin expression. TGF- $\beta 1$ induced a mesenchymal phenotype in the MSS cells (HT29 and SW480), whereas TGF- $\beta 1$ treatment in MSI cells (DLD1 and HCT116) had variable results; a mesenchymal phenotype in DLD1 cells was noted and increased membrane expression of E-cadherin in the HCT116 cells was observed. Nuclear localization of E-cadherin and increased expression of vimentin occurred after $6 \mathrm{~h}$ and increased until $24 \mathrm{~h}$ in the HT29 cells (Fig. 2E).

mRNA expression of E-cadherin and vimentin in the colon cancer cell lines. The four colon cancer cell lines showed decreased E-cadherin or increased vimentin expression following TSA or TGF- $\beta 1$ treatment. These effects were greater in the presence of TGF- $\beta 1$. However, the mRNA expression among the four cell lines showed slight differences (Fig. 3). 
A

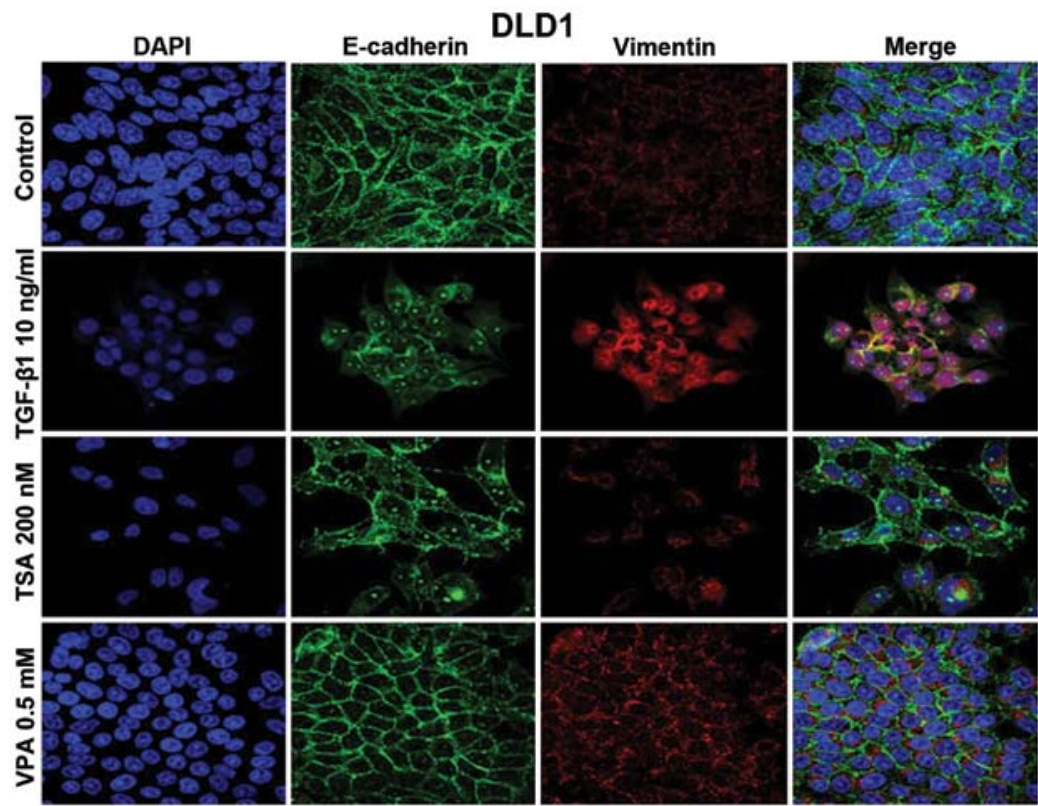

B

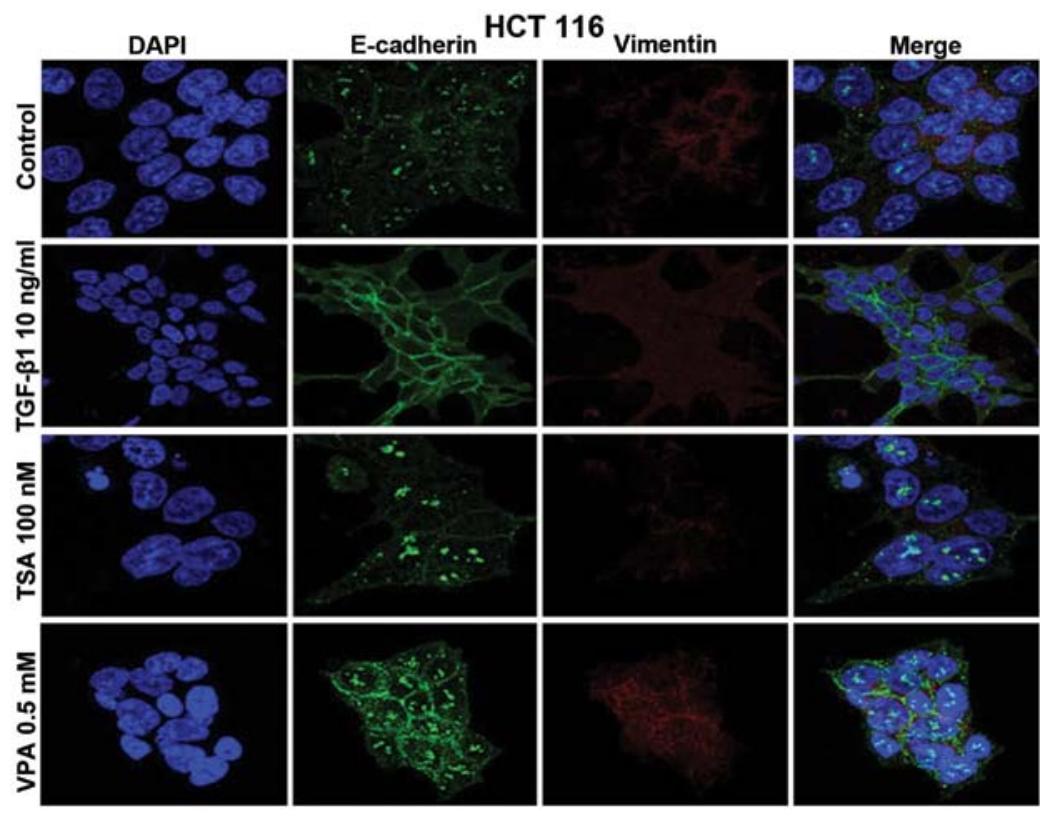

C

SW480

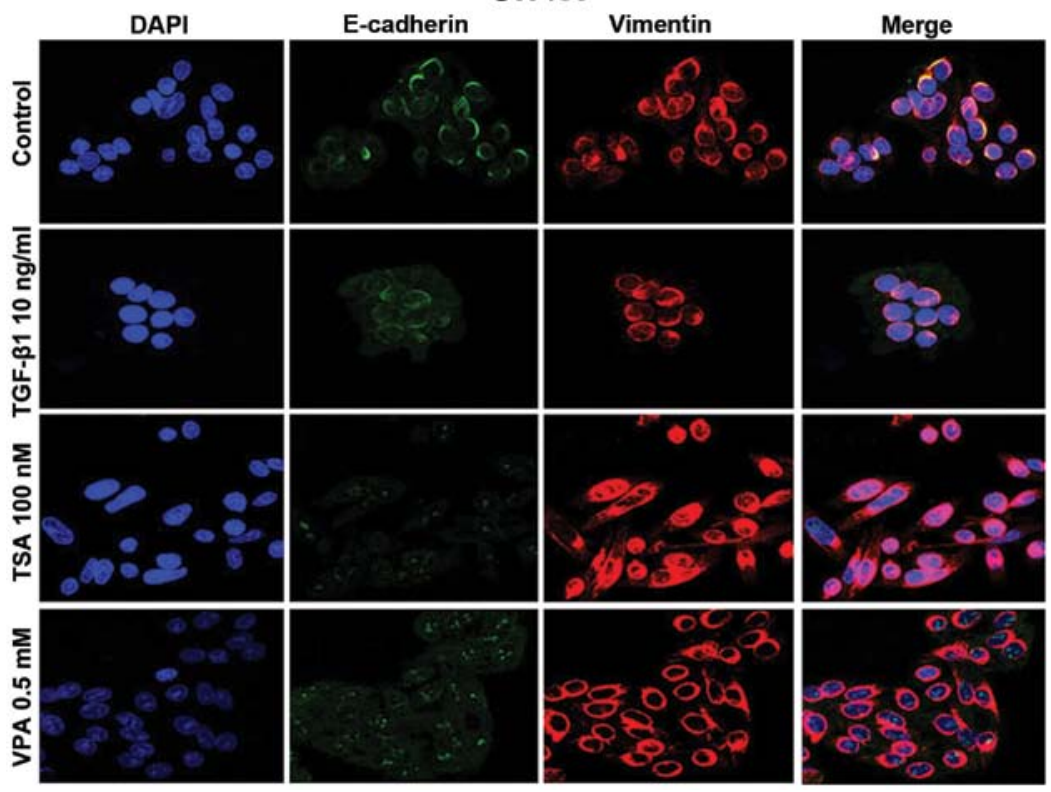


D

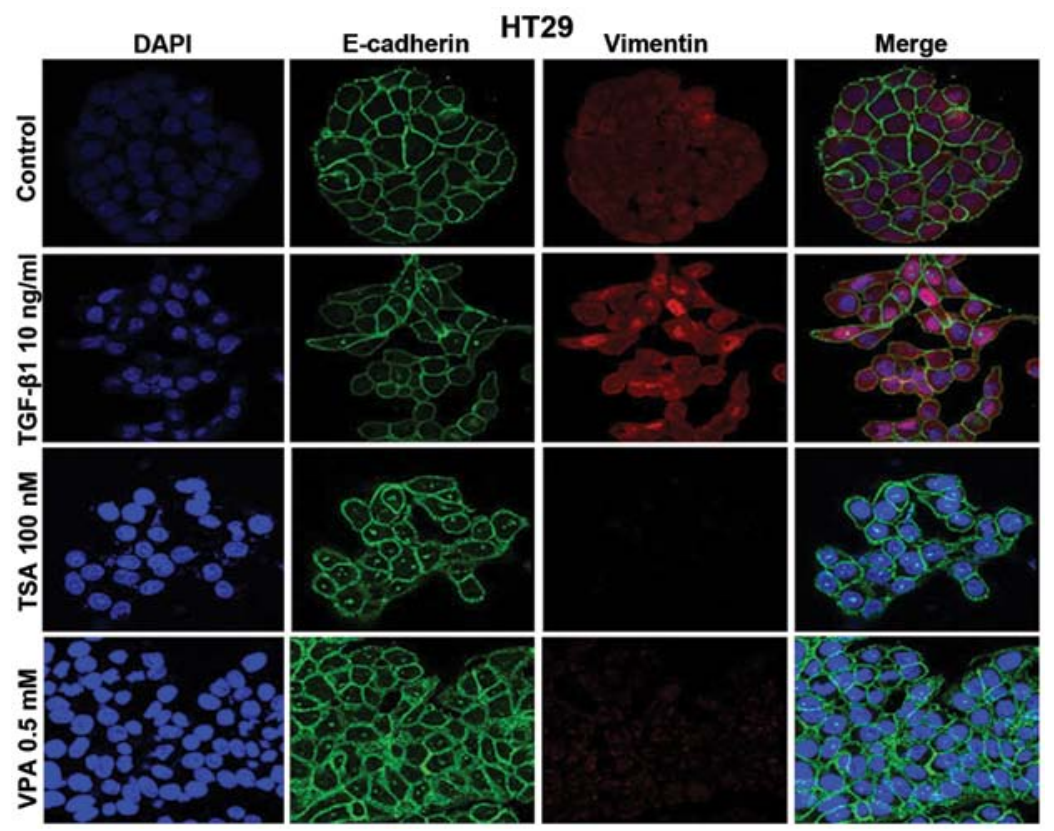

$\mathbf{E}$

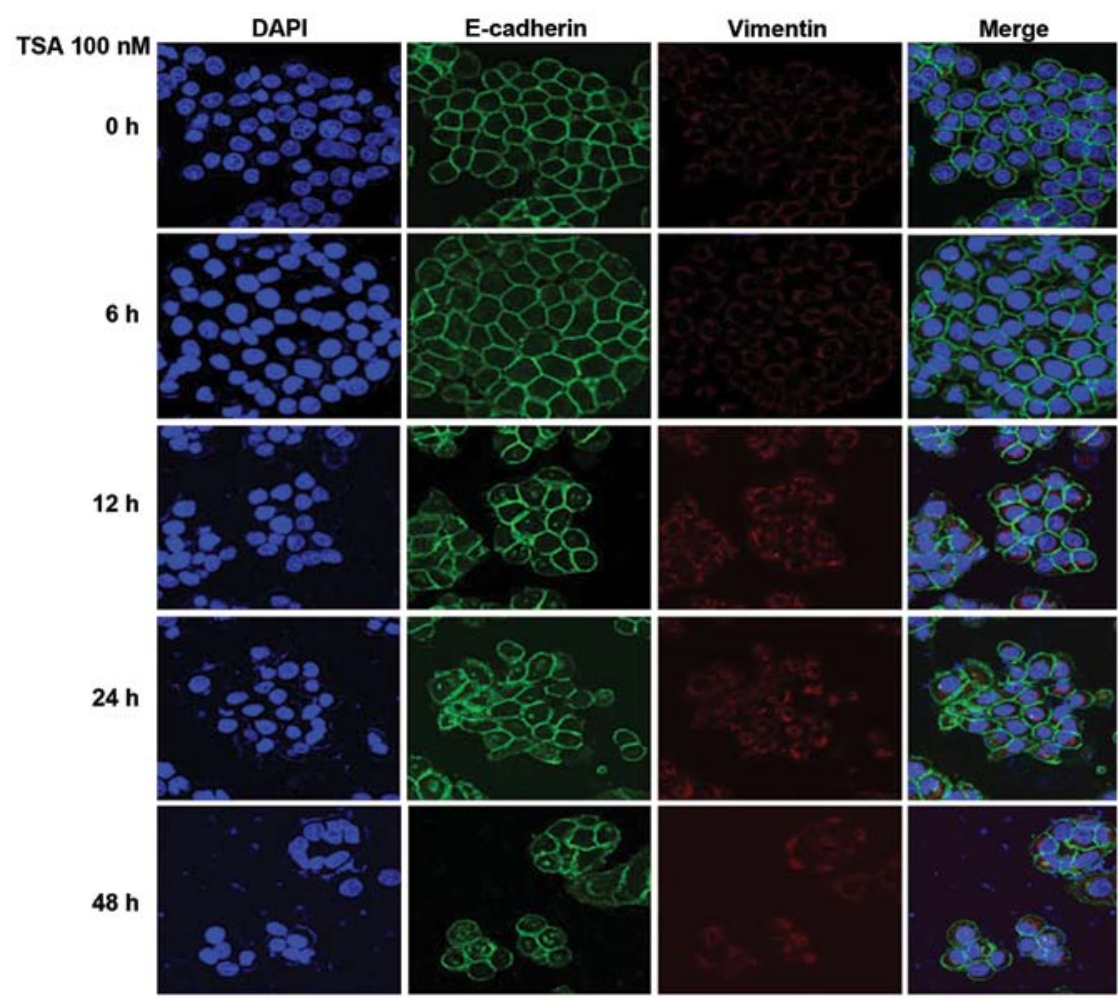

Figure 2. Immunofluorescence microscopy for E-cadherin and vimentin in the four colon cancer cell lines. (A-D) Colon cancer cells treated with TSA or VPA demonstrated attenuation of membrane expression and nuclear translocation of E-cadherin and/or increased vimentin expression compared to the control cells. The responses to TGF- $\beta 1$ treatment were similar in the MSS cells (HT29 and SW480). However, the responses were variable in the MSI cells (DLD1 and HCT116); increased vimentin expression in the DLD1 cells and increased membrane expression of E-cadherin in the HCT116 cells. (E) Immunofluorescence microscopy for E-cadherin and vimentin in the HT29 cells treated with TSA for 0, 6, 12,24 and $48 \mathrm{~h}$. The responses to TSA treatment occurred after $6 \mathrm{~h}$ and increased up to $24 \mathrm{~h}$. E-cadherin (green), vimentin (red), DAPI (blue), and merged images (original magnification, x630).

Protein expression of E-cadherin and vimentin in the colon carcinoma cells. After treatment with HDAC inhibitors, a decrease in E-cadherin and an increase in S100A4 and vimentin expression were noted in the SW480 cells. These changes were enhanced by co-treatment with TGF- $\beta 1$. A decrease in E-cadherin expression was demonstrated following TSA or VPA treatment in the HCT116 and DLD1 cells. Vimentin was increased by co-treatment with the HDAC inhibitors and with TGF- $\beta 1$ in the four cell lines (Fig. 4).

Migration and invasion assays. Single treatment with TSA or VPA did not show a difference in effects compared to the controls. However, the migratory ability increased following VPA and TGF- $\beta 1$ treatment in the DLD1 cells and it increased 

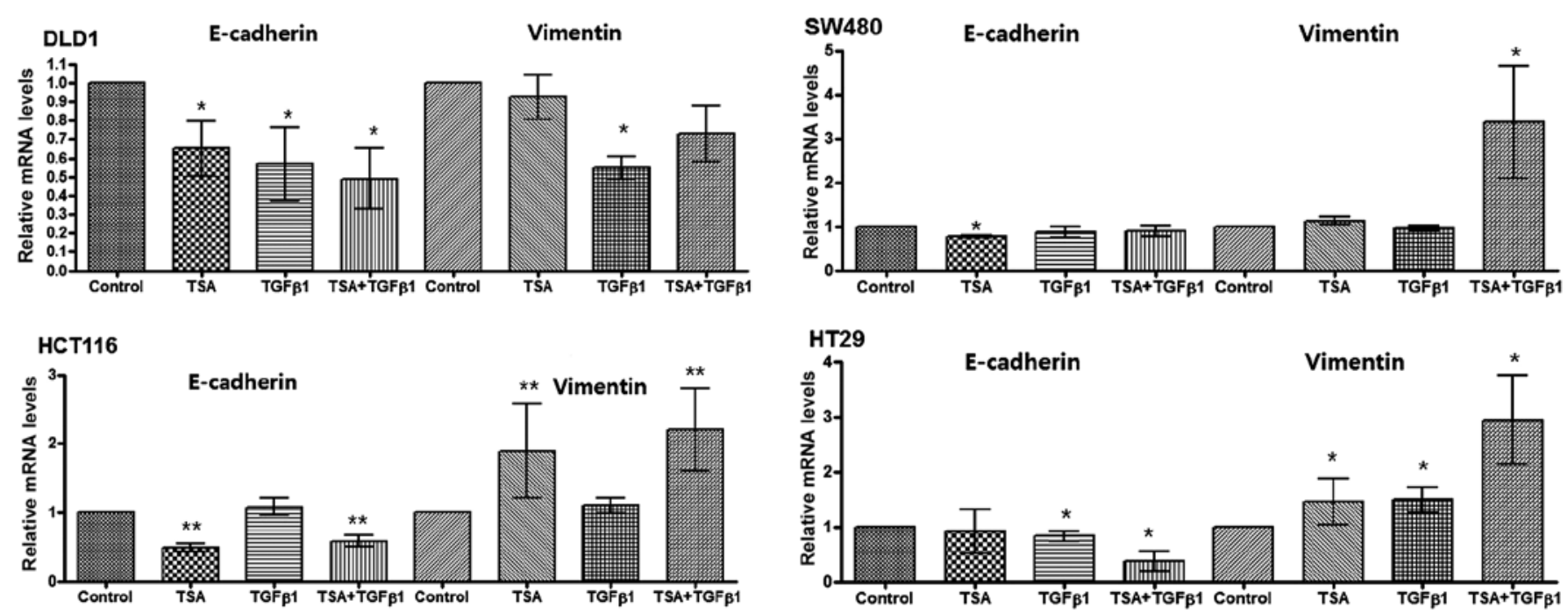

Figure 3. Relative mRNA levels of E-cadherin and vimentin in the four colon cancer cell lines. The four colon cancer cell lines showed decreased E-cadherin and/or increased vimentin expression following TSA treatment when compared to the controls. These effects were greater in the presence of TGF- $\beta 1$. Data are represented as the mean $\pm \mathrm{SE}$. ${ }^{*} \mathrm{P}<0.05$ and ${ }^{* *} \mathrm{P}<0.01$, Mann-Whitney $\mathrm{U}$ test. Relative expression was adjusted to the reference gene GAPDH and measured by real-time quantitative RT-PCR.
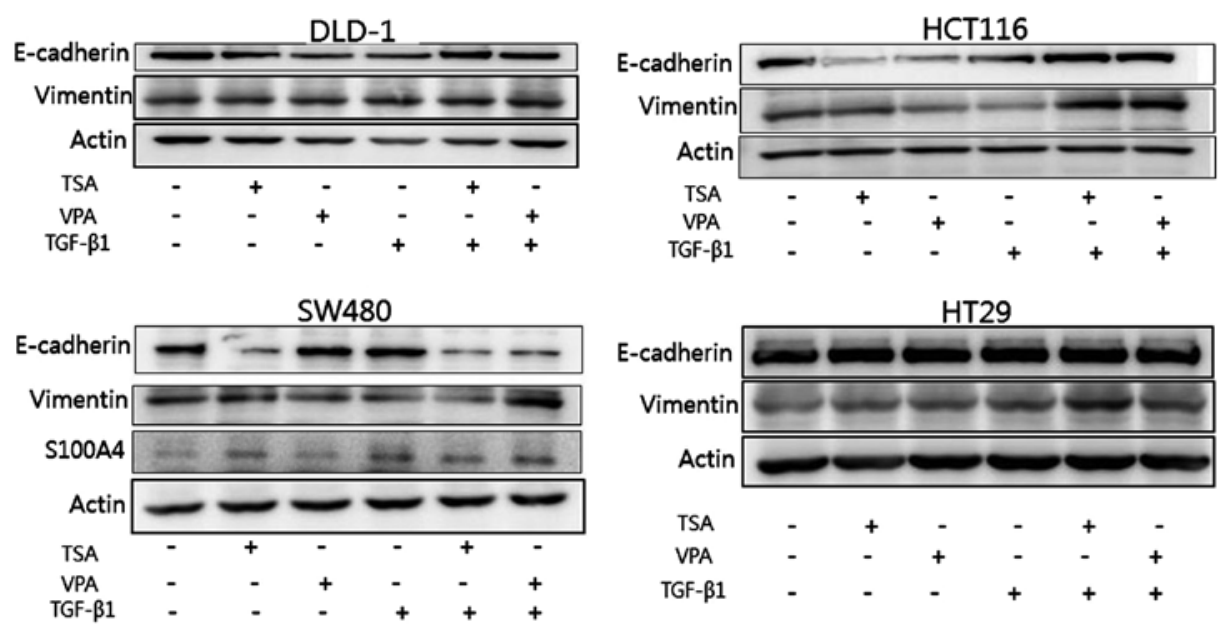

Figure 4. E-cadherin, vimentin and S100A4 protein expression in the four colon cancer cell lines following treatment with TSA or VPA for $24 \mathrm{~h}$. The responses to the HDAC inhibitors included a decrease in E-cadherin and an increase in S100A4 and vimentin expression in the SW480 cells. These changes were enhanced by co-treatment with TGF- $\beta 1$. A decrease in E-cadherin expression was demonstrated in the HCT116 and DLD1 cells following TSA or VPA treatment. Vimentin was increased by co-treatment of HDAC inhibitors and TGF- $\beta 1$ in the four cell lines.

following the TSA or VPA treatment combined with TGF- $\beta 1$ in the SW480 cells (Fig. 5A). These results demonstrated that EMT was enhanced following TSA or VPA treatment in combination with TGF- $\beta 1$.

Invasion was increased by TSA, VPA or TGF- $\beta 1$ treatment compared to no treatment in the DLD1 cells $(\mathrm{P}=0.002$, $\mathrm{P}=0.002$ and $\mathrm{P}=0.001$, respectively). However, invasive ability did not increase following co-treatment with HDAC inhibitors and TGF- $\beta 1$ in the DLD1 cells. Invasion was increased following VPA treatment only when compared to no treatment in the SW480 cells $(\mathrm{P}=0.039)$ (Fig. 5B).

Cell proliferation. Cell proliferation of colon carcinoma cells was assessed following treatment with TSA, VPA or TGF- $\beta 1$ (Fig. 6). TSA (100 nM) or VPA $(0.5 \mathrm{mM})$ did not influence cell proliferation except in the SW480 cells, which exhibited slightly suppressed cell proliferation. TGF- $\beta 1(5 \mathrm{ng} / \mathrm{ml})$ did not have an influence on cell proliferation. However, TGF- $\beta 1(10 \mathrm{ng} / \mathrm{ml})$ enhanced cell proliferation compared to the control except for DLD1 cells, which showed suppressed cell proliferation.

\section{Discussion}

The present study demonstrated that HDAC inhibitors TSA and VPA induced EMT, which was enhanced following TGF- $\beta 1$ co-treatment in the colon cancer cells. The mesenchymal phenotype was determined by reduced expression and nuclear translocation of E-cadherin, and decreased expression of vimentin in the MSS (SW480 and HT29) and MSI (DLD1 and HCT116) cells with variable susceptibility. TSA or VPA also increased cell migration and invasion ability. 
A

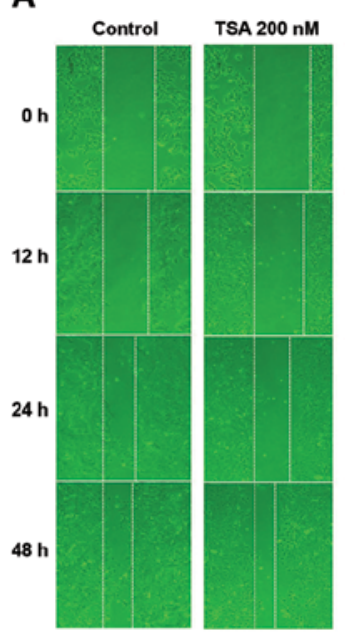

DLD1

VPA $0.5 \mathrm{mM}$ TGF- $\beta 110 \mathrm{ng} / \mathrm{ml}$ TGF- $\beta 1+$ TSA TGF- $\beta 1+$ VPA
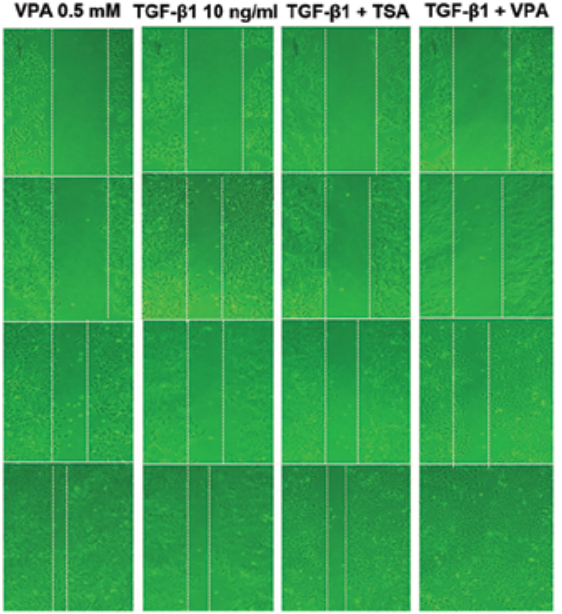
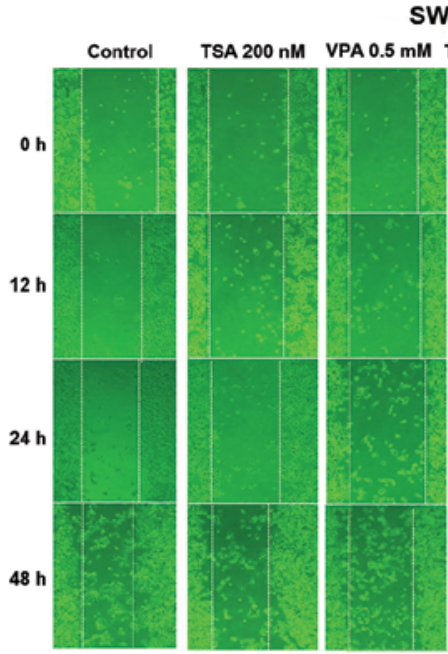

SW480

B DLD1
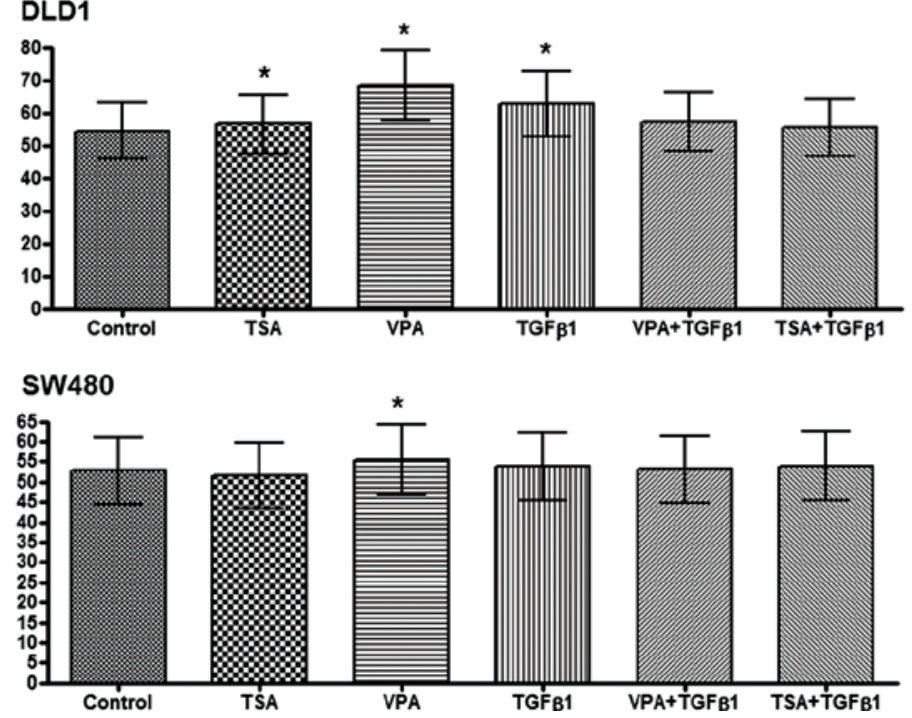

Figure 5. (A) Migration assay in the DLD1 and SW480 cells following treatment with TSA or VPA for $24 \mathrm{~h}$. Single treatment with TSA or VPA did not cause a difference in the migratory ability of the cells when compared to the controls. However, the migratory ability was increased following treatment with VPA and TGF- $\beta 1$ treatment in the DLD1 cells and it was increased in the SW480 cells following TSA or VPA treatment with TGF- $\beta 1$. (B) Invasion assay of DLD1 and SW480 cells treated with TSA or VPA for $24 \mathrm{~h}$. Invasive ability was increased by TSA, VPA or TGF- $\beta 1$ treatment in the DLD1 cells and by VPA treatment in the SW480 cells. However, invasive ability did not increase following a combination with HDAC inhibitors and TGF- $\beta 1$ treatment in the DLD1 cells. Data are represented as the mean $\pm \mathrm{SE}$. ${ }^{*} \mathrm{P}<0.05$ and ${ }^{* *} \mathrm{P}<0.01$, Wilcoxon signed-rank test.
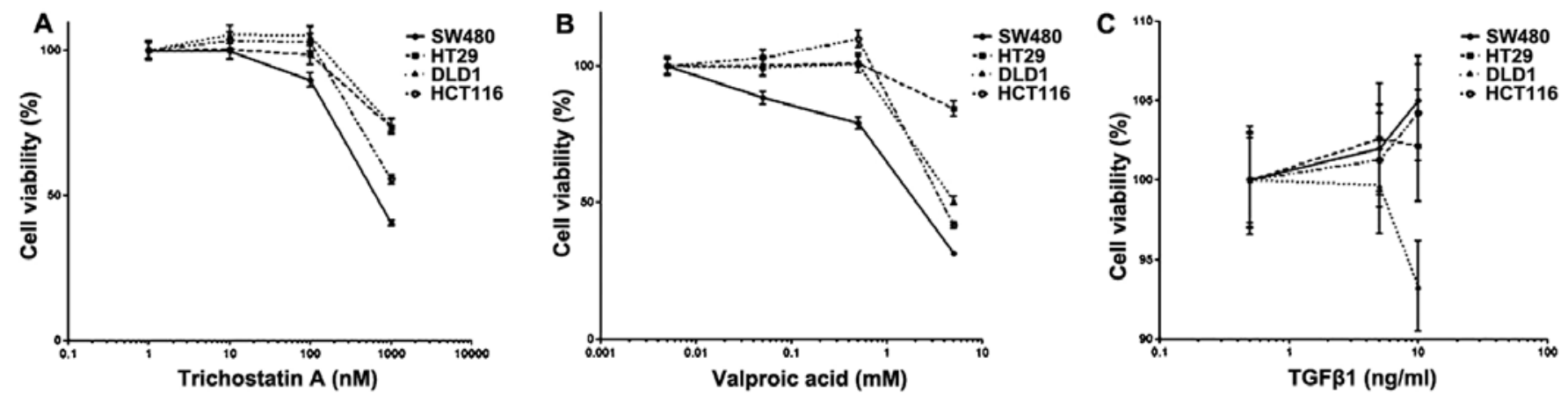

Figure 6. Cell proliferation assay in the four colon cancer cell lines following treatment with (A) TSA, (B) VPA and (C) TGF- $\beta 1$. TSA (100 nM) or VPA $(0.5 \mathrm{mM})$ had no influence on cell proliferation except the SW480 cells, which had slightly suppressed cell proliferation. TGF- $\beta 1$ (5 ng/ml) had no influence on cell proliferation. However, TGF- $\beta 1(10 \mathrm{ng} / \mathrm{ml})$ enhanced cell proliferation except for the DLD1 cells, which showed suppressed cell proliferation.

EMT is a biological process that is encountered in primary mesenchyme, wound healing and carcinoma (27). A hallmark of EMT is the disintegration and disassembly of cell-cell junctions by loss of proteins associated with the polarized 
epithelial phenotype, which normally interacts with the basement membrane via its basal surface, initiating invasive and metastatic behavior. EMT is characterized by loss of proteins, including E-cadherin, ZO-1 and tight junctional molecules, whereas it is characterized by upregulation of vimentin, which is a biomarker of the mesenchymal phenotype.

Many studies have reported that HDAC inhibitors reverse or attenuate EMT through upregulation of E-cadherin in different solid tumors and attenuate TGF- $\beta$-induced EMT in normal epithelial cells. They suggest that HDAC inhibitors may have therapeutic roles in solid cancers and fibrotic disorders by inhibition of EMT.

However, several recent studies reported opposite results that HDAC inhibitors can induce EMT. HDAC inhibitors TSA and vorinostat (suberoylanilidehydroxamic acid, SAHA) were found to induce the EMT phenotype, increasing mesenchymal markers such as vimentin and $\mathrm{N}$-cadherin, concomitant with an increase in the expression of Sox 2 and Nanog, which is associated with cancer stem-cell characteristics in prostate cancer cells (23). They suggest that the mechanisms of EMT induction by HDAC inhibitors are through the activation of promoters of Snail, Slug and Twist1. Inhibition of HDAC by TSA also induced EMT in head and neck squamous cell carcinomas, accumulation of BMI-1, an oncogene associated with tumor aggressiveness, and expression of vimentin (24). Another study showed that HDAC inhibitors induced fibroblast-like morphology, upregulated Snail and vimentin and downregulated E-cadherin in nasopharyngeal carcinoma cells following sodium butyrate $(\mathrm{NaB})$ or SAHA treatment (25). HDAC inhibitor TSA enhanced vimentin gene expression requiring the proximal promoter region including GC-box1, a known Sp1/Sp3 binding site (28). A recent study revealed that SAHA induced EMT during human embryo implantation (29).

The different results in regards to the EMT response to HDAC inhibitor treatment may be related to the balance of gene expression, which includes EMT inducers and EMT suppressors. Studies with cDNA arrays have shown that treatment with HDAC inhibitors leads to a 2-fold or greater change in the expression of $\sim 7-10 \%$ of the genes examined (30). HDAC inhibitor was found to induce about as many genes as were repressed. Whether or not these changes in gene expression result in cell death probably depends upon the cellular context. In addition, the gene expression pattern caused by HDACs on tumors is relatively non-specific (12), which suggests that individual HDAC inhibitors show differing degrees of effectiveness in their action on EMT, even in the same cell type.

The present study found that TSA and VPA induced EMT-like phenotypes in all the CRC cell lines irrespective of MSI, mutation of TGFBR2, K-RAS or APC genes, and tumor aggressiveness. HCT116 cells have wild-type APC and higher malignant potential. DLD1, HT29 and SW480 cells have mutated APC and mutated P53. All cell lines, except HT29, also carry activating mutations in the KRAS gene. Malignant potential was also different in the four CRC cell lines; DLD-1, HT29, HCT116 and SW480, in ascending order (31). The changes in EMT phenotype induced by TGF- $\beta 1$ and HDAC inhibitors were variable according to the different cell type. Mutant or wild-type TGFBR2, APC, and K-RAS proteins were different in the four CRC cell lines. EMT induction by
TGF- $\beta 1$ was greater in the MSS (SW480 and HT29) cells than that in the MSI (DLD1 and HCT116) cells.

The expression of E-cadherin, which suppresses EMT, may prevent invasiveness and metastasis. However, recent studies showed that the shift of E-cadherin localization from the membrane to the cytoplasm or nucleus in CRC was associated with metastasis and poor outcomes in human tissues (32) and animal models (33). A colonic cancer metastasis model showed that E-cadherin proteolysis and nuclear localization were associated with aggressive growth foci in the peritoneal microenvironment. The localization of E-cadherin was also demonstrated in various tumors including Merkel cell carcinoma (34), stomach (35), renal (36), esophageal (37) and solid pseudo-papillary tumors of the pancreas (38). However, most reports of nuclear localization of E-cadherin in cancer concerned studies that utilized immunohistochemistry only, which must be interpreted with caution (39). The mechanism by which the E-cadherin molecule is translocated to the nucleus is currently not clear. The present study showed that TSA and VPA induced nuclear translocation of E-cadherin in the four CRC cell lines with preserved or reduced membrane expression. We suggest that the most important E-cadherin change during EMT process was not the mRNA or protein amounts but the location. The amount of E-cadherin reduction following treatment of HDAC inhibitors was not enough to reach statistical analysis in several cell lines in the present study. A similar result was noted in the previous study, which showed that SAHA treatment in breast cancer cells induced redistribution of E-cadherin from the cell surface to the cytoplasm while preserving total E-cadherin levels (40).

TSA was previously found to prevent TGF- $\beta(5 \mathrm{ng} / \mathrm{ml})$ induced EMT in a concentration-dependent manner in human renal epithelial cells (22) and in mouse hepatocytes (41). TSA treatment induced a fundamental increase in the mRNA levels of ZO-1 and E-cadherin in a concentration-dependent manner, which started to be expressed at doses of $20 \mathrm{ng} / \mathrm{ml}$ of TSA and was most effective at the dose of $400 \mathrm{nM}$ in mouse hepatocytes (41). Cell cytotoxicity and apoptosis were induced at higher doses $(800 \mathrm{nM})$, and had no effect at lower doses $(200 \mathrm{nM})(19)$. These results suggest that the effect of TSA on EMT begins at a low dosage, prior to apoptosis and inhibition of proliferation, although the dosage differs according to cell type and cancer progression. We used TSA (100 or $200 \mathrm{nM})$ at a level that induces mild suppression of cell proliferation while preserving cell viability. The concentration of VPA was fixed at $0.5 \mathrm{mM}$, which is in the range of low toxicity in the human (42).

Pharmacological inhibitors of class I and II HDAC activity (HDAC inhibitors) are potent inducers of growth arrest, differentiation and apoptosis of colon cancer cells in vitro and in vivo. Studies of HDAC inhibitors on colon cancer cells have attempted to identify the improvements in response, and potential efficacy with conventional chemotherapeutics and their tolerable cytotoxicity. Many studies have reported that HDAC inhibitors have an effective action against colon cancer cells with a synergistic effect together with radiation or targeted therapies (6). VPA and TSA inhibit proliferation in colon cancer cells and have been shown to have far greater selective toxicity to tumor cells (43). However, the present study demonstrated that HDAC inhibitor TSA or VPA can induce the EMT of CRC cells, alone or in combination with TGF- $\beta 1$. 
These results should be considered when using combination treatment of HDAC inhibitors and other chemotherapies.

\section{Acknowledgements}

The present study was supported by a grant from the National R\&D Program for Cancer Control, Ministry of Health and Welfare, Republic of Korea (1120330) and a National Research Foundation of Korea grant funded by the Korea government (NRF-2013R 1A 1A 2063994).

\section{References}

1. Jung KW, Park S, Kong HJ, Won YJ, Lee JY, Seo HG and Lee JS: Cancer statistics in Korea: incidence, mortality, survival, and prevalence in 2009. Cancer Res Treat 44: 11-24, 2012.

2. Tsai HL, Chu KS, Huang YH, Su YC, Wu JY, Kuo CH, Chen CW and Wang JY: Predictive factors of early relapse in UICC stage I-III colorectal cancer patients after curative resection. J Surg Oncol 100: 736-743, 2009.

3. Lee SJ, Choi SY, Kim WJ, Ji M, Lee TG, Son BR, Yoon SM, Sung R, Lee EJ, Youn SJ and Park SM: Combined aberrant expression of E-cadherin and S100A4, but not $\beta$-catenin is associated with disease-free survival and overall survival in colorectal cancer patients. Diagn Pathol 8: 99, 2013.

4. He X, Chen Z, Jia M and Zhao X: Downregulated E-cadherin expression indicates worse prognosis in Asian patients with colorectal cancer: evidence from meta-analysis. PLoS One 8: e70858, 2013.

5. Findlay VJ, Wang C, Watson DK and Camp ER: Epithelial-tomesenchymal transition and the cancer stem cell phenotype: insights from cancer biology with therapeutic implications for colorectal cancer. Cancer Gene Ther 21: 181-187, 2014.

6. Mariadason JM: HDACs and HDAC inhibitors in colon cancer. Epigenetics 3: 28-37, 2008.

7. Chen X, Wong P, Radany E and Wong JY: HDAC inhibitor, valproic acid, induces p53-dependent radiosensitization of colon cancer cells. Cancer Biother Radiopharm 24: 689-699, 2009.

8. Meng J, Zhang HH, Zhou CX, Li C, Zhang F and Mei QB: The histone deacetylase inhibitor trichostatin A induces cell cycle arrest and apoptosis in colorectal cancer cells via p53-dependent and -independent pathways. Oncol Rep 28: 384-388, 2012.

9. Hsu YF, Sheu JR, Lin CH, Yang DS, Hsiao G, Ou G, Chiu PT, Huang YH, Kuo WH and Hsu MJ: Trichostatin A and sirtinol suppressed survivin expression through AMPK and p38MAPK in HT29 colon cancer cells. Biochim Biophys Acta 1820: 104-115, 2012.

10. Xiong H, Du W, Zhang YJ, Hong J, Su WY, Tang JT, Wang YC, Lu R and Fang JY: Trichostatin A, a histone deacetylase inhibitor, suppresses JAK2/STAT3 signaling via inducing the promoterassociated histone acetylation of SOCS1 and SOCS3 in human colorectal cancer cells. Mol Carcinog 51: 174-184, 2012.

11. Habold C, Poehlmann A, Bajbouj K, Hartig R, Korkmaz KS, Roessner A and Schneider-Stock R: Trichostatin A causes p53 to switch oxidative-damaged colorectal cancer cells from cell cycle arrest into apoptosis. J Cell Mol Med 12: 607-621, 2008.

12. Marchion D and Munster P: Development of histone deacetylase inhibitors for cancer treatment. Expert Rev Anticancer Ther 7: 583-598, 2007.

13. Mologni L, Cleris L, Magistroni V, Piazza R, Boschelli F, Formelli F and Gambacorti-Passerini C: Valproic acid enhances bosutinib cytotoxicity in colon cancer cells. Int J Cancer 124: 1990-1996, 2009.

14. DI Fazio P, Montalbano R, Quint K, Alinger B, Kemmerling R, Kiesslich T, Ocker M and Neureiter D: The pan-deacetylase inhibitor panobinostat modulates the expression of epithelialmesenchymal transition markers in hepatocellular carcinoma models. Oncol Lett 5: 127-134, 2013.

15. Shah P, Gau Y and Sabnis G: Histone deacetylase inhibitor entinostat reverses epithelial to mesenchymal transition of breast cancer cells by reversing the repression of E-cadherin. Breast Cancer Res Treat 143: 99-111, 2014.

16. Srivastava RK, Kurzrock R and Shankar S: MS-275 sensitizes TRAIL-resistant breast cancer cells, inhibits angiogenesis and metastasis, and reverses epithelial-mesenchymal transition in vivo. Mol Cancer Ther 9: 3254-3266, 2010.
17. Taylor MD, Liu Y, Nagji AS, Theodosakis N and Jones DR: Combined proteasome and histone deacetylase inhibition attenuates epithelial-mesenchymal transition through E-cadherin in esophageal cancer cells. J Thorac Cardiovasc Surg 139: 1224-1232, 2010.

18. Meng F, Sun G, Zhong M, Yu Y and Brewer MA: Anticancer efficacy of cisplatin and trichostatin A or 5-aza-2'-deoxycytidine on ovarian cancer. Br J Cancer 108: 579-586, 2013.

19. Kaimori A, Potter JJ, Choti M, Ding Z, Mezey E and Koteish AA: Histone deacetylase inhibition suppresses the transforming growth factor beta1-induced epithelial-to-mesenchymal transition in hepatocytes. Hepatology 52: 1033-1045, 2010.

20. Xiao W, Chen X, Liu X, Luo L, Ye S and Liu Y: Trichostatin A, a histone deacetylase inhibitor, suppresses proliferation and epithelial-mesenchymal transition in retinal pigment epithelium cells. J Cell Mol Med 18: 646-655, 2014.

21. Chen X, Xiao W, Chen W, Luo L, Ye S and Liu Y: The epigenetic modifier trichostatin A, a histone deacetylase inhibitor, suppresses proliferation and epithelial-mesenchymal transition of lens epithelial cells. Cell Death Dis 4: e884, 2013.

22. Yoshikawa M, Hishikawa K, Marumo T and Fujita T: Inhibition of histone deacetylase activity suppresses epithelial-tomesenchymal transition induced by TGF-beta1 in human renal epithelial cells. J Am Soc Nephrol 18: 58-65, 2007.

23. Kong D, Ahmad A, Bao B, Li Y, Banerjee S and Sarkar FH: Histone deacetylase inhibitors induce epithelial-to-mesenchymal tranasition in prostate cancer cells. PLoS One 7: e45045, 2012.

24. Giudice FS, Pinto DS Jr, Nör JE, Squarize CH and Castilho RM: Inhibition of histone deacetylase impacts cancer stem cells and induces epithelial-mesenchyme transition of head and neck cancer. PLoS One 8: e58672, 2013.

25. Jiang GM, Wang HS, Zhang F, Zhang KS, Liu ZC, Fang R, Wang H, Cai SH and Du J: Histone deacetylase inhibitor induction of epithelial-mesenchymal transitions via up-regulation of Snail facilitates cancer progression. Biochim Biophys Acta 1833: 663-671, 2013.

26. Pino MS, Kikuchi H, Zeng M, Herraiz MT, Sperduti I, Berger D, Park DY, Iafrate AJ, Zukerberg LR and Chung DC: Epithelial to mesenchymal transition is impaired in colon cancer cells with microsatellite instability. Gastroenterology 138: 1406-1417, 2010.

27. Kalluri R and Weinberg RA: The basics of epithelial-mesenchymal transition. J Clin Invest 119: 1420-1428, 2009.

28. Wu Y, Zhang X, Salmon M and Zehner ZE: The zinc finger repressor, ZBP-89, recruits histone deacetylase 1 to repress vimentin gene expression. Genes Cells 12: 905-918, 2007.

29. Uchida H, Maruyama T, Nishikawa-Uchida S, Oda H, Miyazaki K, Yamasaki A and Yoshimura Y: Studies using an in vitro model show evidence of involvement of epithelialmesenchymal transition of human endometrial epithelial cells in human embryo implantation. J Biol Chem 287: 4441-4450, 2012.

30. Xu WS, Parmigiani RB and Marks PA: Histone deacetylase inhibitors: molecular mechanisms of action. Oncogene 26: 5541-5552, 2007

31. Gujral TS and MacBeath G: A system-wide investigation of the dynamics of Wnt signaling reveals novel phases of transcriptional regulation. PLoS One 5: e10024, 2010.

32. Elzagheid A, Algars A, Bendardaf R, Lamlum H, Ristamaki R, Collan Y, Syrjanen K and Pyrhonen S: E-cadherin expression pattern in primary colorectal carcinomas and their metastases reflects disease outcome. World J Gastroenterol 12: 4304-4309, 2006.

33. Céspedes MV, Larriba MJ, Pavón MA, Alamo P, Casanova I, Parreño M, Feliu A, Sancho FJ, Muñoz A and Mangues R: Site-dependent E-cadherin cleavage and nuclear translocation in metastatic colorectal cancer model. Am J Pathol 177: 2067-2079, 2010.

34. Han AC, Soler AP, Tang CK, Knudsen KA and Salazar H: Nuclear localization of E-cadherin expression in Merkel cell carcinoma. Arch Pathol Lab Med 124: 1147-1151, 2000.

35. Moon KC, Cho SY, Lee HS, Jeon YK, Chung JH, Jung KC and Chung DH: Distinct expression patterns of E-cadherin and beta-catenin in signet ring cell carcinoma components of primary pulmonary adenocarcinoma. Arch Pathol Lab Med 130: 1320-1325, 2006.

36. Gervais ML, Henry PC, Saravanan A, Burry TN, Gallie BL, Jewett MA, Hill RP, Evans AJ and Ohh M: Nuclear E-cadherin and VHL immunoreactivity are prognostic indicators of clearcell renal cell carcinoma. Lab Invest 87: 1252-1264, 2007. 
37. Salahshor S, Naidoo R, Serra S, Shih W, Tsao MS, Chetty R and Woodgett JR: Frequent accumulation of nuclear E-cadherin and alterations in the Wnt signaling pathway in esophageal squamous cell carcinomas. Mod Pathol 21: 271-281, 2008.

38. Serra S, Salahshor S, Fagih M, Niakosari F, Radhi JM and Chetty R: Nuclear expression of E-cadherin in solid pseudopapillary tumors of the pancreas. JOP 8: 296-303, 2007.

39. Ordonez NG: Value of E-cadherin and N-cadherin immunostaining in the diagnosis of mesothelioma. Hum Pathol 34: 749-755, 2003.

40. Robertson FM, Woodward WA, Pickei R, Ye Z, Bornmann W, Pal A, Peng Z, Hall CS and Cristofanilli M: Suberoylanilide hydroxamic acid blocks self-renewal and homotypic aggregation of inflammatory breast cancer spheroids. Cancer 116: 2760-2767, 2010 .
41. Lei W, Zhang K, Pan X, Hu Y, Wang D, Yuan X, Shu G and Song J: Histone deacetylase 1 is required for transforming growth factor-beta1-induced epithelial-mesenchymal transition. Int J Biochem Cell Biol 42: 1489-1497, 2010.

42. Manoguerra AS, Erdman AR, Woolf AD, Chyka PA, Caravati EM, Scharman EJ, Booze LL, Christianson G, Nelson LS, Cobaugh DJ and Troutman WG: Valproic acid poisoning: an evidence-based consensus guideline for out-of-hospital management. Clin Toxicol (Phila) 46: 661-676, 2008.

43. Insinga A, Monestiroli S, Ronzoni S, Gelmetti V, Marchesi F, Viale A, Altucci L, Nervi C, Minucci S and Pelicci PG: Inhibitors of histone deacetylases induce tumor-selective apoptosis through activation of the death receptor pathway. Nat Med 11: 71-76, 2005. 